\title{
Celiac Disease: Comparison of Oberhuber Classification and Corazza- Villanacci Classification
}

\author{
Shikha Ghanghoria, Sachin Sharma* and Priya Jain \\ Department of pathology Mahatma Gandhi memorial medical College, Indore (M.P) India
}

\begin{abstract}
Background: Celiac disease occurs in genetically predisposed individuals on consumption of certain grains. The diagnosis is based on biopsy showing the presence of characteristic histological changes in duodenum and jejunum that improve after gluten free diet. The Oberhuber Classification is very widely used by pathologists. The new Corazza-Villanacci Classification simplifies the criteria.

Methods: Retrospectively diagnosed 200 patients of Celiac disease according to Oberhuber classification over duration of 05 years were considered. The 200 cases were retrieved from the records and were sent to two pathologists, who were blinded to each other and were not given any clinical information. Each pathologist received the set of biopsy specimens on two separate occasions and had reclassified them according to both grading systems in a random order. The interobserver variation was then determined after re-examination according to Oberhuber classification and after using to Corazza-Villanacci classification too
\end{abstract}

Result: Mean kappa values were 0.77 (good) for the Oberhuber classification versus 0.98 (very good) for the Corazza -Villanacci classification

Conclusion: The Corazza-Villanacci classification gives better interobserver agreement compared with the Oberhuber classification and contributes to the validity of diagnosis in celiac disease.

Keywords: Celiac Disease, Oberhuber classification, Corazza-Villanacci classification

\section{Introduction}

Celiac disease occurs in genetically predisposed individuals on consumption of certain grains including wheat. ${ }^{[1,2]}$ The characteristic histological changes seen in duodenum and jejunum that improve after gluten free diet thus making the diagnosis. ${ }^{[2,4]}$ In 1992 Marsh classify morphological changes secondary to gluten sensitivity enteropathy, which was later amended by Oberhuber in $1999^{[5]}$ The presence of greater diagnostic categories in the Oberhuber classification leading to lower reproducibility of the diagnosis. ${ }^{[3,4,8]}$ The new Corazza-Villanacci Classification reduces the number of categories and as per the review of literature variation between the observers is also reduced. ${ }^{[2,3,4,8]}$

\section{Materials and Methods}

The aim of the study is to assess the interobserver agreement and to observe the reproducibility of the MarshOberhuber classification and the newer Corazza -Villanacci classification system in patients of Celiac disease.

The present study was a retrospective one and comprised of 200 patients who were already diagnosed as Celiac disease according to Marsh Oberhuber classification over duration of 05 years.

The 200 cases were retrieved from the records and were sent to two pathologists, who were blinded to each other and were not given any clinical information. Each pathologist received the set of biopsy specimens on two separate occasions and had reclassified them according to both grading systems in a random order. Then the initial diagnosis reported as per the Marsh Oberhuber classification was also noted.

The interobserver variation was then determined among the two pathologists for the diagnosis made after reexamination according to Marsh Oberhuber classification and after using to Corazza and Villanacci classification too.

The kappa values were used to assess agreement between two pathologists using SPSS 20 .O software. The strength of agreement as regards the kappa values was evaluated according to Landis and Koch revised by Altman as follows: poor 0.20; fair 0.21- 0.40 ; moderate $0.41-0.60$; good 0.61-0.80; and very good $0.81-1.00$.

\section{Result}

The celiac disease histological alterations, morphological changes, grading the presence of immunological disorders with architectural changes of the mucosa is integrated in Oberhuber classification. ${ }^{[6]}$ Table 1 showing comparison of Histopathological classifications of mucosal changes associated with celiac disease. 
The initial diagnosis for the 200 cases according to Marsh Oberhuber classification were as follows in the figure 1. When reclassified according to the Marsh Oberhuber classification, following were the results of both the pathologists as shown in the figure 2 and 3 . When classified according to the Corazza and Villanacci classification, following were the results of both the pathologists as shown in the figure 4 and 5.

Table 1. Comparison of Histopathological classifications of mucosal changes associated with celiac disease ( Bao, 2012 )[7]

\begin{tabular}{|c|c|c|c|}
\hline \multicolumn{2}{|c|}{ Marsh-Oberhuber Classification (1992) later amended in 1999} & \multicolumn{2}{|r|}{ Corazza-Villanacci Classifications (2005) } \\
\hline Type 1 & $\begin{array}{l}\text { Villi and normal crypt architecture } \\
\text { With } \geq 30 \text { IELs / } 100 \text { enterocytes }\end{array}$ & Grade A & $\begin{array}{l}\text { No atrophy, normal villous architecture } \\
\text { with or without crypt hyperplasia and } \\
\geq 25 \text { IELs / } 100 \text { enterocytes }\end{array}$ \\
\hline Type 2 & $\begin{array}{l}\text { Normal villous architecture , crypt } \\
\text { Hyperplasia and } \geq 30 \text { IELs / } 100 \\
\text { enterocytes }\end{array}$ & & \\
\hline Type 3a & $\begin{array}{l}\text { Partial villous atrophy with crypt / villi ratio of }<3: 1 \\
\text { or } 2: 1 \text {, crypt } \\
\text { Hyperplasia and } \geq 30 \text { IELs / } 100 \\
\text { enterocytes }\end{array}$ & Grade B1 & $\begin{array}{l}\text { Atrophic, with villi / crypt ratio of }<3: 1 \text {, } \\
2: 1 \text { or } 1: 1 \text {, villi still detectable and } \geq 25 \\
\text { IELs / } 100 \text { enterocytes }\end{array}$ \\
\hline Type 3b & $\begin{array}{l}\text { Subtotal villous atrophy with } \\
\text { Villi / crypt of }<1: 1 \text {, crypt hyperplasia and } \geq 30 \\
\text { IELs / } 100 \text { enterocytes }\end{array}$ & & \\
\hline Type 3c & $\begin{array}{l}\text { Total villous atrophy ( flat mucosa) } \\
\text { With marked crypt hyperplasia and } \\
\geq 30 \text { IELs / } 100 \text { enterocytes }\end{array}$ & Grade B2 & $\begin{array}{l}\text { Completely flat atrophic mucosa, no } \\
\text { Observable villi and } \geq 25 \text { IELs / } 100 \\
\text { enterocytes }\end{array}$ \\
\hline Type 4 & $\begin{array}{l}\text { Hypoplastc atrophic lesion ( flat } \\
\text { Mucosa ) with only a few crypts and near-normal } \\
\text { IEL count }\end{array}$ & Eliminated & \\
\hline
\end{tabular}

\section{Pathologist 1:-}

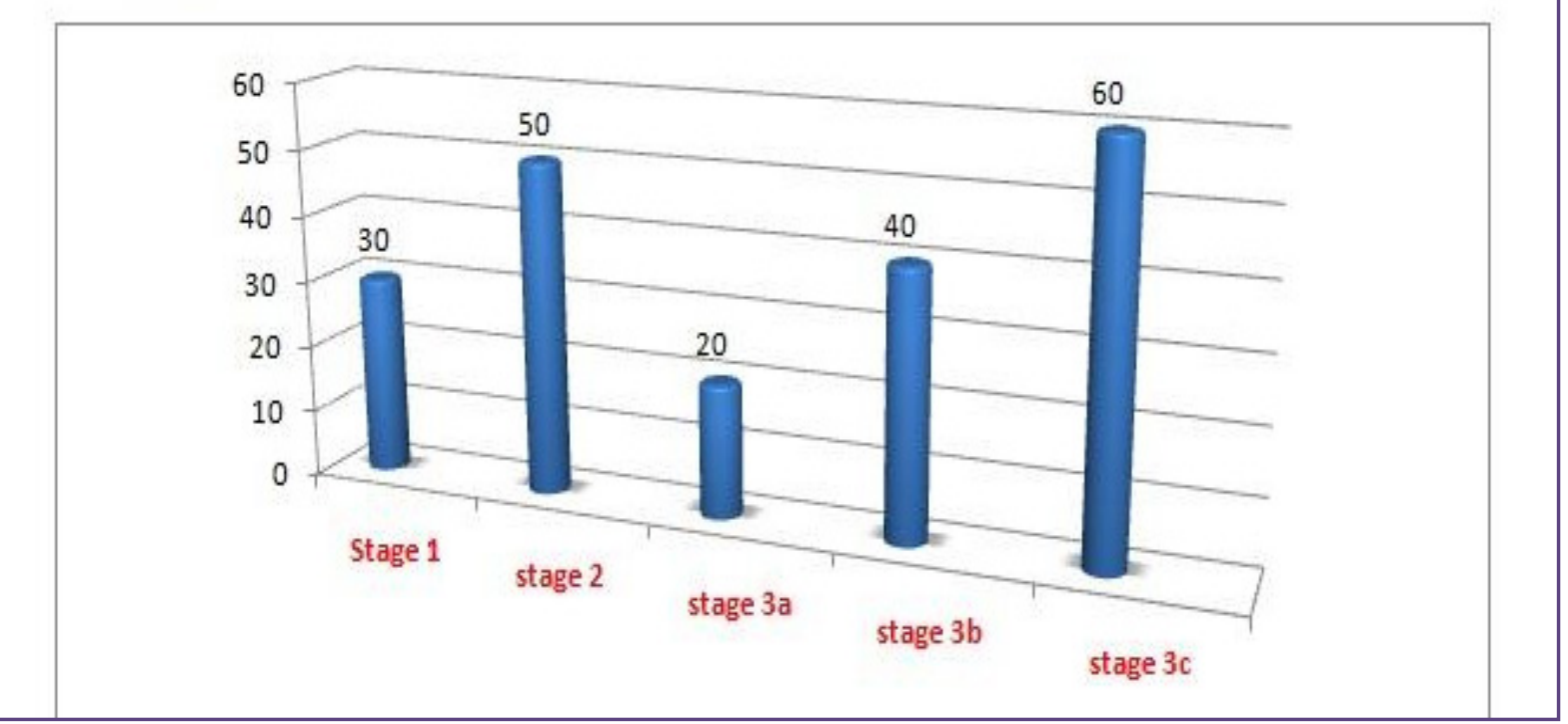

Fig. 1: The initial diagnosis for the 200 cases according to Marsh Oberhuber classification were as follows in the figure 1. 


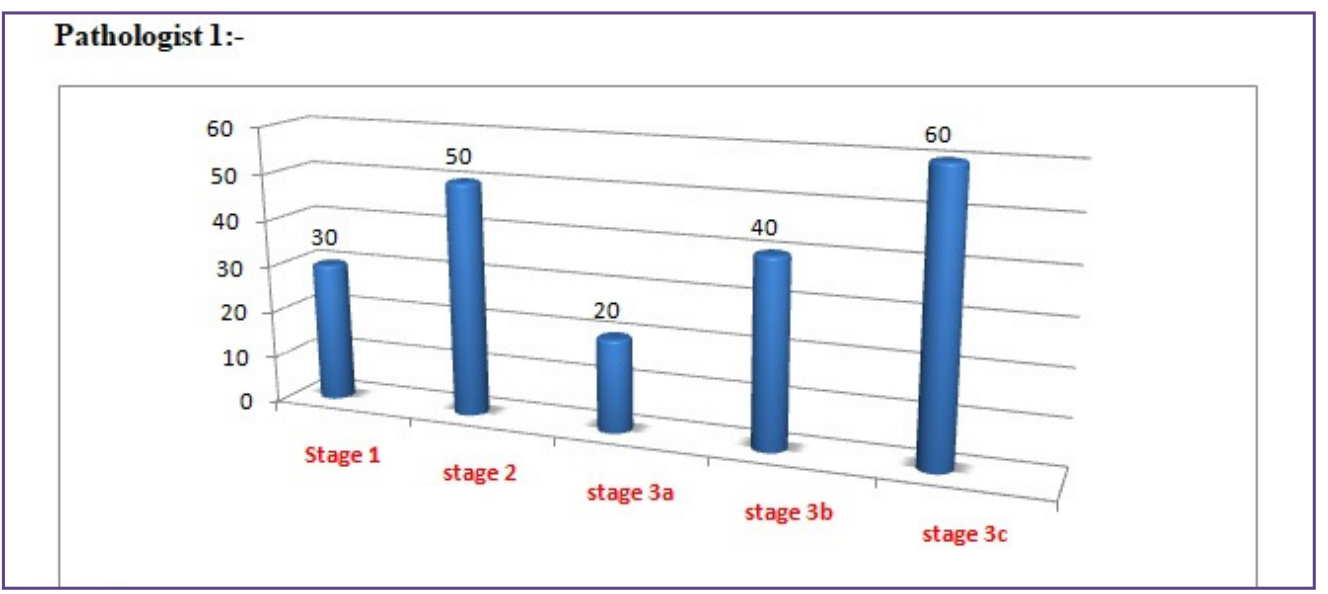

fig. 2: When reclassified according to the Marsh Oberhuber classification, following were the results of both the pathologists as shown in the figure 2 and 3.

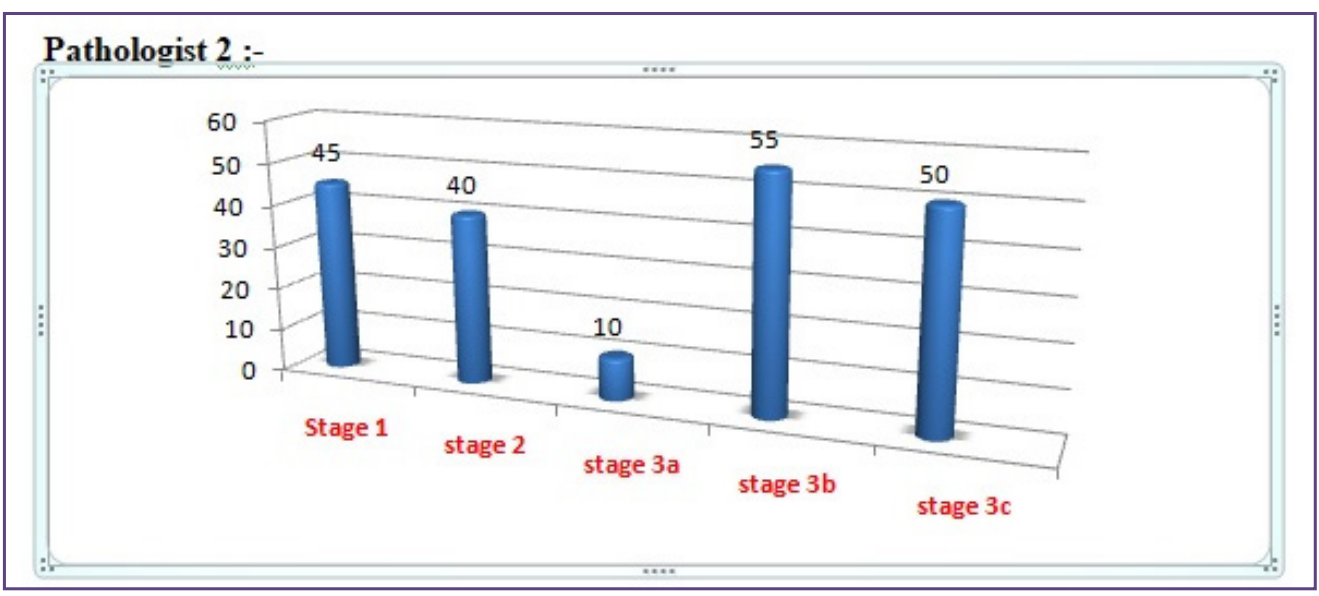

Fig. 3; When reclassified according to the Marsh Oberhuber classification , following were the results of both the pathologists as shown in the figure 2 and 3.

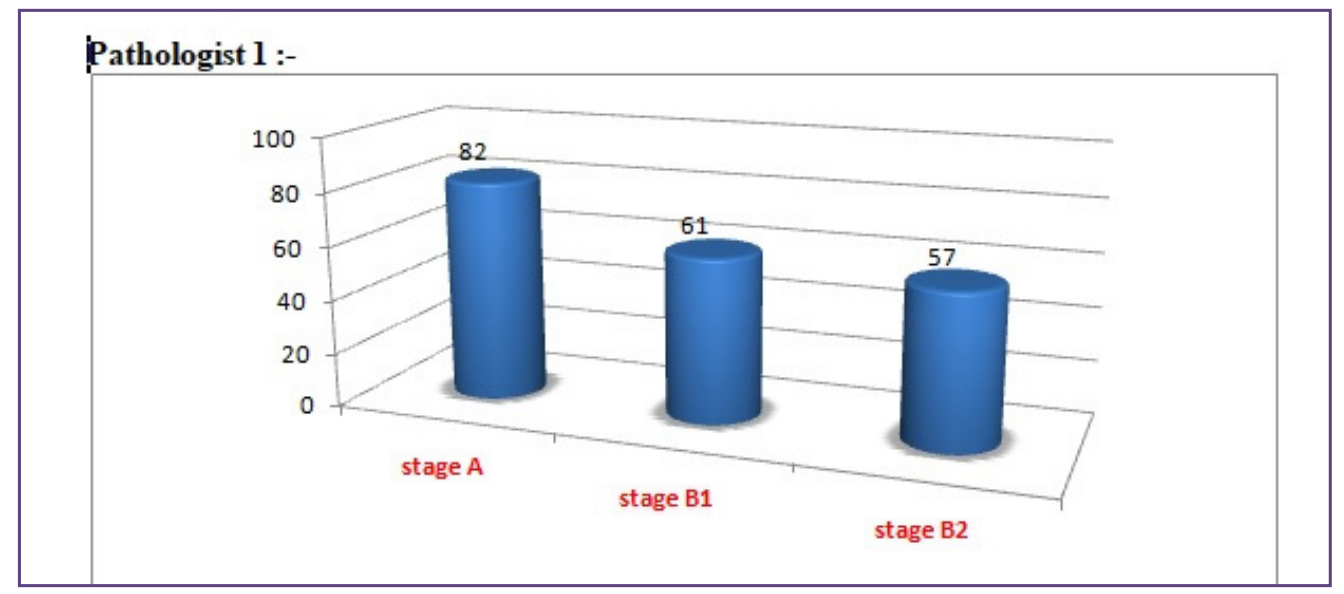

Fig. 4; When classified according to the Corazza and Villanacci classification, following were the results of both the pathologists as shown in the figure 4 and 5. 


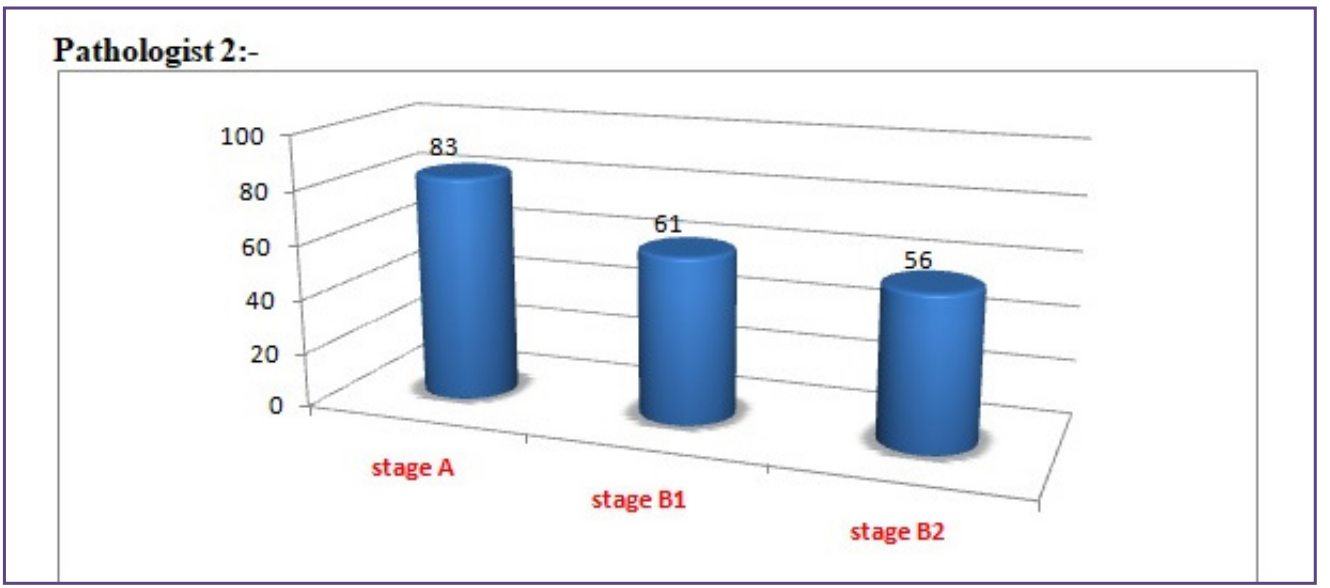

Fig. 5: When classified according to the Corazza and Villanacci classification, following were the results of both the pathologists as shown in the figure 4 and 5.

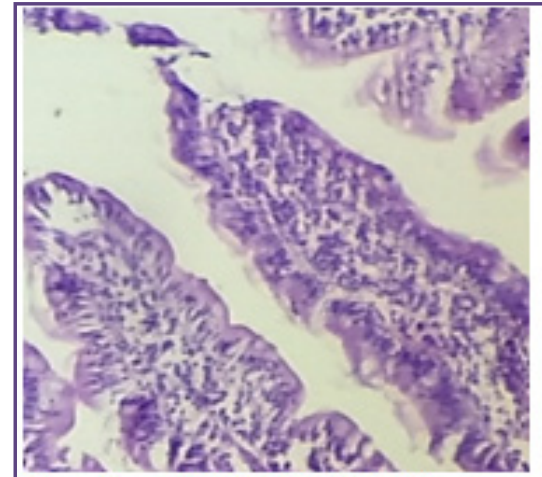

Fig .6 I (GRADE A)

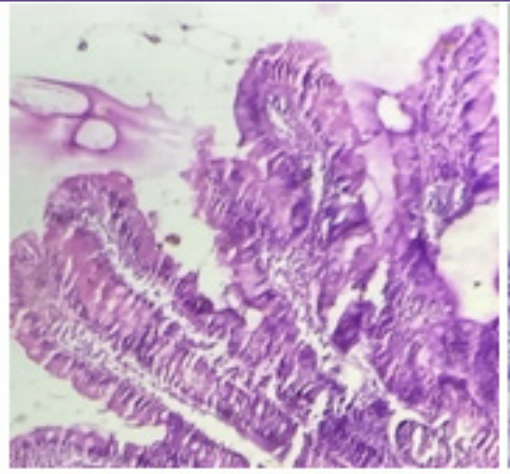

Fig. 7 II (GRADE A)

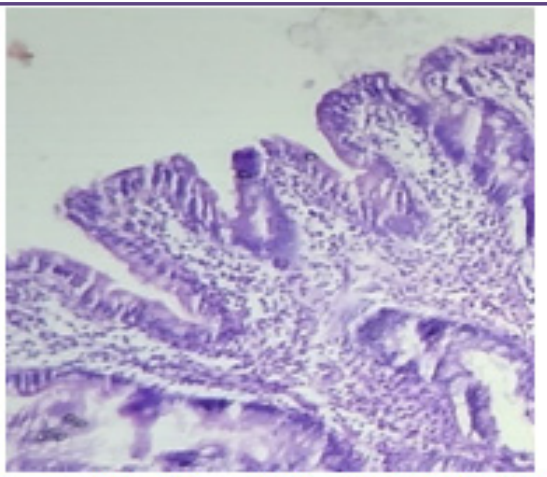

Fig.8

IIIa (GRADEB1)

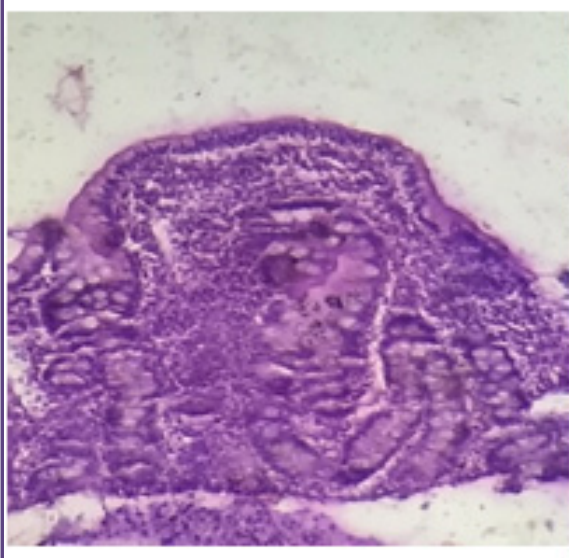

Fig 9 IIIb (GRADE B1)

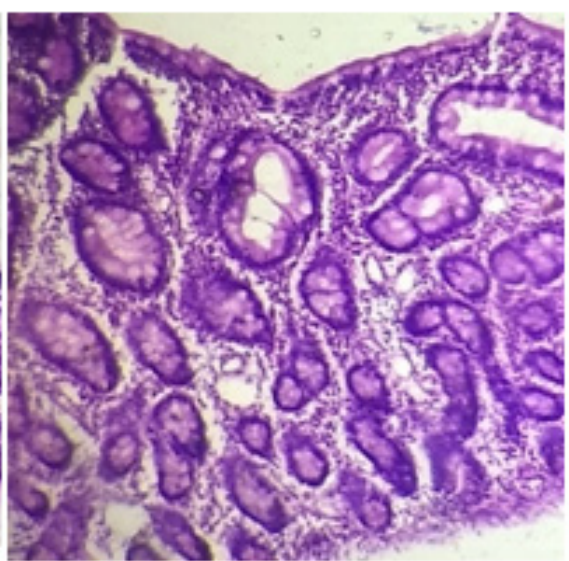

Fig.10 III c (GRADE B2)

Fig. 6,7,8,9 and 10 shows histological changes both according to Marsh-Oberhuber classification and CorazzaVillanacci classification. ( H \& E staining). 
Overall, mean kappa values were 0.77 (good) for the Marsh-Oberhuber classification versus 0.98 (very good) for the Corazza and Villanacci classification system.

\section{Discussion}

Drute et al has graded severity of changes in the Celiac disease by villous / crypt ratio which is $>2.5$ in normal mucosa and in his series he has graded celiac disease from grade I to grade IV and observed that after induction of gluten free diet and higher grades are reverted to grade I or normal ${ }^{[9]}$

The modified Marsh classification system has been widely used for the classification of Celiac disease. This system is efficacious and is valid under optimal clinical conditions $[2,4,10,11,12]$. The modified Marsh classification has greater number of diagnostic categories; leads to lower agreement between the observers which results in misclassification. It is obvious that the reliability of any diagnostic classification system is always a matter of concern because the poor reliability leads to substantial number of cases will be misclassified. ${ }^{[13]}$

In the Corazza-Villanacci classification, due to the reduction of the categories and hence a consequent reduction in the subjective variation (in seeing whether the villi are mildly atrophic or markedly atrophic but not yet completely flat), there tends to be better agreement among the various pathologists. ${ }^{[14]}$ (Fig4 \&5)

In our study we found that interobserver variation when Celiac disease was classified according to Modified Marsh classification system was more. This could be due to the subjective differences in the recognition of villous abnormalities. The final diagnosis rests on the improvement of the symptoms / serological values / biopsy findings after gluten free diet. ${ }^{[2,4,8,10]}$

The last category of Marsh classification (type IV) has been omitted and made obsolete by a recent finding of an aberrant IEL clone characteristically seen in enteropathy type intestinal $\mathrm{T}$ cell lymphoma, refractory sprue and ulcerative jejunoileitis ${ }^{[2,4,10]}$ No case was reported as type IV in our study too. (Fig1) Figure 6,7,8,9 and 10 shows histological changes both according to Marsh-Oberhuber classification and Corazza- Villanacci classification.

\section{Conclusion}

For classifying Celiac disease the various classification systems are ever evolving each with its merits and demerits. There is greater subjective variation found in Modified Marsh classification system. The new classification system proposed by Corazza and Villanacci simplify the above classification leading to more interobserver agreement and hence greater diagnostic reproducibility compared with the more cumbersome Marsh-Oberhuber classification and contributes to the validity of diagnosis in Celiac disease.

The uniformity in the diagnosis is facilitated by routine use of simplified grading system which in turn facilitate the relationship between pathologists and clinicians and validity of the pathologic diagnosis of Celiac disease thus increases.

\section{Reference}

1. Dicke WK, Weijers HA, van de Kamer JH. Coeliac disease, II: the presence in wheat of a factor having a deleterious effect in cases of celiac disease. Acta Paediatr. 1953;42(1):34-42.

2. Bao F, Green PHR, Bhagat G. An update on celiac disease histopathology and the road ahead. Arch Pathol Lab Med.2012;136:735-45.

3. Villanacci V, Ceppa P, Tavani E, Vindigni C, Volta U. Coeliac disease: The histology report. Digestive and liver disease. 2011;43S:385-95.

4. Corazza GR, Villanacci V. Coeliac disease. J Clin Pathol.2005;58:573-74.

5. Oberhuber G, Granditsch G, Vogelsang H. The histopathology of celiac disease: tme for a standardized report scheme for pathologists. Eur J Gastroenterol Hepatol.1999;11:1185-94. http://dx.doi.org/10.1097/00042737-199910000-00019

6. Brenes-Pino F, Herrera A. Small Intestne Biopsy and its Interpretaton: Preliminary Results in Costa Rica. In Rodrigo L and Pena AS, editors. Celiac Disease and Non-Celiac Gluten Sensitvity. Barcelona, Spain: OmniaScience;2014.p.203-218.

7. Bao F, Bhagat G. Histopathology of celiac disease. Gastrointest Endosc Clin North Am. 2012;22:679-94.http:// dx.doi.org/10.1016/j.giec.2012.07.001

8. Ensari A. Gluten-Sensitive Enteropathy (Celiac Disease): Controversies in Diagnosis and Classification. Arch Pathol Lab Med.2010;134(6):826-36

9. Drut R, Rua EC. The histopathology of pediatric celiac disease: order must prevail out of chaos. Int J Surg Path2001,9:261-264

10. Bhasin TS, Mannan R, Malhotra V, Sood N, Sood A. Bhatia PK. Hiatological recovery profiles of patients with celiac disease- An Indian perspective. J Clin Diagn Res .2010;4:2217-25.

11. Brown IS, Smith J, Rosty C. Gastrointestinal pathology in Celiac Disease: A Case series of 150 Consecutive newly diagnosed patients. Am J Clin Pathol.2012;138(1):42-9.

12. Corazza GR, Villanacci V, Zambelli C, Milione M, Luinetti $\mathrm{O}$, Vindigni $\mathrm{C}$, et al. Comparision of the interobserver reproducibility with different histologic criteria used in celiac disease. Clin Gastroenterol Hepatol.2007;5:838-43. 
13. Gino RC, * Vincenzo V, $\$$ Claudia $\mathrm{Z}, \ddagger$ Massimo $\mathrm{M}, \S$ Ombretta L, Carla V, $\uparrow$ et all Comparison of the Interobserver Reproducibility with Different Histologic Criteria Used in Celiac Disease clinical gastroenterology and hepatology 2007;5:838-843

14. Manas $M \alpha$, Sanjay $\mathrm{P} \sigma$, Manisha $\mathrm{S} \rho$, Tejinder SB GD, Mridu M¥, Harjot K et all Celiac Disease: An Assessment of
Subjective Variation and Diagnostic Reproducibility of the Various Classification Systems Global Journal of Medical Research: C Microbiology and Pathology Volume 15 Issue 1 Version 1.0 Year 2015 Type: Double Blind Peer Reviewed International Research Journal Publisher: Global Journals Inc. (USA) Online ISSN: 22494618 \& Print ISSN: 0975588810. Serra S, Jani PA. An approach to duodenal biopsies. J Clin Pathol.2006;59:1133-50.

*Corresponding author:

Dr. Sachin Sharma, Mahatma Gandhi Memorial Medical College Campus, A.B Road, Indore (M.P.), Pincode- 452001 INDIA

Phone: +91 9009575021

Email: amandiagnostic@gmail.com

Financial or other Competing Interests: None. 